\title{
A Educação Ambiental no Ensino de Administração: desafios e perspectivas
}

\author{
Suzana de Oliveira Malta* \\ Humberto Calloni** $^{* *}$
}

\begin{abstract}
Resumo
Formar administradores comprometidos com a questão ambiental e atuantes nas organizações constitui-se como um dos desafios atuais para as Instituições de Ensino Superior. Este artigo pretende contribuir com a reflexão sobre o processo de inserção da Educação Ambiental nos cursos de graduação em Administração. Ele apresenta uma contextualização de alguns marcos do desenvolvimento do ensino de Administração no Brasil e da Educação Ambiental para, em seguida, apresentar um panorama de como essa temática tem sido trabalhada no ensino superior e, mais especificamente, no ensino de Administração.

Palavras-chave: Educação Ambiental; Ensino de Administração; Desafios; Perspectivas.
\end{abstract}

\section{Environmental Education in Administration teaching: challenges and perspectives}

\begin{abstract}
Training administrators committed to the environmental issue and active in organizations is one of the current challenges for higher education institutions. This article intends to contribute with the reflection on the process of insertion of Environmental Education in the undergraduate courses in Administration. It presents a contextualization of some of the milestones of the development of the teaching of Administration in Brazil and of Environmental Education to then present a panorama of how this theme has been worked in higher education and, more specifically, in the teaching of Administration.

Keywords: Environmental Education; Teaching of Administration; Challenges; Perspectives.
\end{abstract}

\section{Introdução}

Jacobi (2005) destaca que vivemos, no início do século XXI, uma emergência que, mais que ecológica, é uma crise do estilo de pensamento, dos imaginários sociais, dos pressupostos epistemológicos e do conhecimento que sustentaram a modernidade. Uma crise do ser no mundo que se manifesta em toda sua plenitude: nos espaços internos do sujeito, nas condutas sociais autodestrutivas; e nos espaços externos, na degradação da natureza e da qualidade de vida das pessoas.

Tendo em vista que o administrador é um profissional que atua diretamente nas questões do cotidiano das organizações, e que muitas vezes desempenha papéis decisoriais dentro das mesmas, torna-se necessário abrir na sua formação um espaço para que sejam discutidos, levantados e analisados todos os riscos e impactos ambientais do modo de vida das sociedades industriais modernas. É importante trabalhar com uma mudança de valores e de postura, de forma que os mesmos possam contribuir de forma mais efetiva para a resolução de questões socioambientais.

Sob essa perspectiva, as atividades a serem desenvolvidas pelos administradores ficam cada vez

*Endereço Eletrônico: suzanamalta @ hotmail.com

** Endereço Eletrônico: hcalloni@mikrus.com.br mais abstratas, mais intelectualizadas, mais autônomas, coletivas e complexas. Vivemos tempos em que a busca de soluções adequadas para um desenvolvimento equilibrado, nos campos econômico e social, tem sido alvo de constantes e inadiáveis discussões, dentro de um ambiente de crescente complexidade e permanente mudança. Para enfrentar tal desafio, um importante papel é destinado ao ensino empresarial e, por consequência, às instituições de ensino superior.

Segundo Alvarez, Philippi Jr. e Alvarenga (2010), a problemática ambiental ocupa na atualidade lugar privilegiado para as discussões do avanço do conhecimento, considerando os desafios teórico-metodológicos que encerra, assim como os desafios para soluções de problemas gerados pela forma como o capitalismo se desenvolve, articulado a uma tecnociência que o sustenta em detrimento dos benefícios para as relações homem-natureza.

Para Gonçalves-Dias, Teodósio e Carvalho (2009) a formação de administradores é um dos campos da educação nos quais os desafios de mudança do comportamento ambiental se apresentam de maneira mais decisiva. Esses desafios não são só relativos à compreensão do comportamento e da dinâmica de construção da consciência ambiental entre os futuros 
administradores, mas também quanto ao desenvolvimento de propostas didático-pedagógicas que possam fazer avançar o ensino-aprendizagem em gestão.

Percebe-se que, geralmente, durante a atuação dos profissionais de administração, eles não se deparam com questões simples para resolver, assim como as soluções para os problemas encontrados não ficam restritos a apenas uma área do conhecimento. Deste modo, o aluno deve estar preparado para solucionar os problemas que a vida em sociedade irá colocar-lhe, isto é, problemas complexos; para analisar criticamente as organizações, antecipando e promovendo suas transformações e possuir responsabilidade social e ambiental, justiça e ética profissional.

\section{O contexto do ensino de Administração no Brasil}

Segundo Giroletti (2005), a Administração institucionalizou-se e profissionalizou-se no Brasil após um longo processo, tendo o mesmo iniciado com a criação de disciplinas de Administração ensinadas em vários cursos superiores. Prosseguiu com a criação dos primeiros cursos de Economia e Administração e consolidou-se com a sua autonomização como curso de graduação e, finalmente, com os diversos cursos de pósgraduação implantados no Brasil a partir da década de 1970.

O contexto para a formação do administrador no Brasil começou a ganhar contornos mais claros na década de quarenta. A partir desse período, acentua-se a necessidade de mão-de-obra qualificada e, consequentemente, da profissionalização do ensino de Administração. De acordo com essa visão, tratava-se de formar, a partir do sistema escolar, um administrador profissional, apto para dar suporte a questões econômicas e administrativas, em uma sociedade que passava de um estágio agrário para a industrialização.

Andrade (1997) destaca que em 1945 surgiram os primeiros resultados quanto à implantação desse ensino. Nesse ano, Gustavo Capanema, Ministro da Educação e Saúde, encaminhou à Presidência da República um documento que propunha a criação de dois cursos universitários: Ciências Contábeis e Ciências Econômicas. O documento afirmava que as atividades de direção e orientação, tanto nos negócios públicos como nos empresariais, haviam atingido um nível de maior complexidade, exigindo de seus administradores e técnicos conhecimentos especializados. Isso possibilitou que os cursos de Economia passassem a ter um caráter de especialização, não mais de natureza genérica, como anteriormente.

O surto de ensino superior, e em especial o de Administração, é fruto da relação que existe entre a expansão que ocorreu na industrialização e o tipo de desenvolvimento econômico adotado após 1964, calcado na tendência para a grande empresa. Nesse contexto, tais empresas, equipadas com tecnologia complexa e com um crescente grau de burocratização, passam a requerer mão-de-obra de nível superior para lidar com essa realidade.

Pode-se apontar a Fundação Getúlio Vargas como a pioneira, enquanto instituição de ensino superior, na criação do primeiro currículo especializado em Administração, tanto pública (através da Escola de Administração Pública EBAP/FGV-1952) quanto de empresas (Escola de Administração de Empresas de São Paulo - EAESP/FGV-1954).A criação da Fundação Getúlio Vargas ocorreu em um momento em que o ensino superior brasileiro deslocava-se de uma tendência européia para uma tendência norte-americana. Isto é evidente, uma vez que a FGV tem apresentado um vínculo entre seus organizadores e o ensino universitário norte-americano, de onde proveio a inspiração para estruturá-la em termos de fundação (ANDRADE, 1997).

Como fruto dessas relações, foi criada, em 1952, a Escola Brasileira de Administração Pública (EBAP), pela Fundação Getúlio Vargas, com o apoio da ONU e da UNESCO para a manutenção inicial. O convênio com esses organismos internacionais previa a manutenção de professores estrangeiros na escola e bolsas de estudo para o aperfeiçoamento dos futuros docentes no exterior.

Com o surgimento da EBAP no Rio de Janeiro, conforme destaca Pizzinatto (1992), a FGV preocupou-se em criar uma escola destinada especificamente à preparação de administradores de empresas, vinculada ao mundo empresarial, com o objetivo de formar especialistas em técnicas modernas de administração empresarial. Essa situação possibilitou a criação da Escola de Administração de Empresas de São Paulo (EAESP), em 1954. Para dar início às atividades nessa nova Instituição, a FGV firmou um acordo com a USAID (Desenvolvimento Internacional do Governo dos Estados Unidos). Nesse convênio, o governo norteamericano se comprometia a manter, junto a esta escola, uma missão universitária de especialistas em Administração de Empresas, recrutados na 
Universidade Estadual de Michigan. Por outro lado, a FGV enviaria docentes para estudos de pósgraduação nos Estados Unidos, com intuito de preencher os quadros do corpo docente da EAESP. Tal convênio revelava a influência do ensino de Administração norte-americano na realidade brasileira, evidenciada, sobretudo, por meio dos currículos e bibliografias.

A partir da década de sessenta, a FGV passou a criar cursos de pós-graduação nas áreas de Economia, Administração Pública e de Empresas. Em meados dessa década, iniciou a oferta regular dos cursos de mestrado. A missão universitária norte-americana atuou na EAESP até 1965, fornecendo uma forte estrutura acadêmica à instituição que lhe permitiu ocupar uma posição dominante entre os cursos de Administração do país.

A Universidade de São Paulo surgiu em 1934, por meio da aglutinação de faculdades já existentes e da abertura de novos centros de ensino. Em 1946, foi criada a Faculdade de Economia e Administração (FEA), que tinha por objetivo formar funcionários para os grandes estabelecimentos de Administração pública e privada. A criação da FEA se deve principalmente ao grande surto de industrialização, quando surgiram empresas movimentando vultosos capitais que exigiram, para sua gestão, técnicas altamente especializadas. A FEA foi criada com um objetivo prático e bem definido: atender, por meio da preparação de recursos humanos, às demandas oriundas do acelerado crescimento econômico.

O surgimento da FGV e da USP, de acordo com Andrade (1997), marcaram o ensino e a pesquisa de temas econômicos e administrativos no Brasil, contribuindo para o processo de desenvolvimento econômico do país. Tais instituições ocuparam uma posição dominante no campo das instituições de ensino de Administração, assim como de referência do posterior desenvolvimento desses cursos.

Observa-se que a criação e a evolução dos cursos de Administração na sociedade brasileira, no seu primeiro momento, se deram no interior de Instituições Universitárias, fazendo parte de um complexo de ensino e pesquisa. Essas escolas transformaram-se em polos de referência para a organização e funcionamento desse campo. No final dos anos 60, a expansão dos Cursos de Administração ocorreria, não mais vinculada a Instituições Universitárias, mas às Faculdades Isoladas que proliferaram no bojo do processo de expansão privatizada na sociedade brasileira.

Para Andrade (1997) essa expansão também está relacionada às transformações ocorridas no plano econômico. A partir da década de 60 , o estilo de desenvolvimento privilegiou as grandes unidades produtivas na economia do país. Ocorreu o crescimento acentuado das grandes empresas, principalmente estrangeiras e estatais, permitindo a utilização crescente da técnica. Isso implicou diretamente a necessidade de profissionais com treinamento específico para executar diferentes funções internas das organizações. Diante dessa situação, as grandes empresas passaram a adotar a profissionalização de seus quadros, tendo em vista o tamanho e complexidade das estruturas. Isso veio constituir um espaço potencial para a utilização dos administradores que passaram pelo sistema escolar.

Essa relação entre prática profissional e a obtenção de título específico impulsionou aqueles que aspiravam a ter acesso a funções econômicoadministrativas, em órgãos públicos ou privados, a ingressar em centros de ensino que oferecessem tal habilitação. Também aqueles que já desenvolviam tais atividades no mercado profissional foram estimulados a buscar o título universitário para obter promoções.

Após 1980 a realidade da área de Administração é repleta de desafios e dificuldades. $\mathrm{O}$ ambiente externo se caracteriza por ser complexo e mutável e as empresas não conseguem decifrá-lo e interpretá-lo de forma adequada. Nessa fase as empresas lutam com a escassez de recursos, dificuldade na colocação de seus produtos e serviços, acirrada concorrência, dificuldade em entender as reações do mercado e as ações dos concorrentes. Assim, ocorre a incerteza quanto ao que poderá acontecer em um futuro próximo ou remoto.

Esse cenário desencadeou uma nova realidade para as organizações, que passaram a conviver em um ambiente onde ordem e desordem caminham juntas e a competitividade provoca a necessidade de adaptação contínua e o estabelecimento de novos padrões de desempenho.

As transformações ocorridas nas últimas décadas do século XX trouxeram uma nova dinâmica nas relações das organizações com o ambiente onde atuam. A instabilidade desencadeou um processo de mudança contínua. Entretanto, nem sempre as relações empresariais foram permeadas por essa necessidade de mudança. Pode-se afirmar que a evolução do pensamento administrativo foi marcada por grandes rupturas no que se refere aos 
princípios que direcionam as práticas de gestão empresarial. Passamos de uma visão racional, mecanicista e estática para uma perspectiva dinâmica, orgânica e complexa.

Toda a evolução ocorrida no ensino de Administração no país mostra as preocupações com a necessidade de um aperfeiçoamento constante, na busca de uma adequação a uma sociedade em contínua mutação, devendo também envolver-se com a ideologia e filosofia de educação da IES que oferece o curso. O currículo deve não só adequar-se às necessidades do mercado de trabalho, mas também constituir-se em "agente transformador e promotor de novas relações produtivas e sociais" (ANDRADE, 1997).

Segundo as novas diretrizes curriculares para os cursos de Administração, estabelecidas através da Resolução MEC no 04/2005 de $13 / 07 / 2005$, em seu artigo $5^{\circ}$, os cursos de graduação em Administração deverão contemplar, em seus projetos pedagógicos e em sua organização curricular, conteúdos que revelem inter-relações com a realidade nacional e internacional, segundo uma perspectiva histórica e contextualizada de sua aplicabilidade no âmbito das organizações e do meio através da utilização de tecnologias inovadoras e que atendam aos seguintes campos interligados de formação:

I - Conteúdos de Formação Básica: relacionados com estudos antropológicos, sociológicos, filosóficos, psicológicos, ético-profissionais, políticos, comportamentais, econômicos e contábeis, bem como os relacionados com as tecnologias da comunicação e da informação e das ciências jurídicas;

II - Conteúdos de Formação Profissional: relacionados com as áreas específicas, envolvendo teorias da administração e das organizações e a administração de recursos humanos, mercado e marketing, materiais, produção e logística, financeira e orçamentária, sistemas de informações, planejamento estratégico e serviços;

III - Conteúdos de Estudos Quantitativos e suas Tecnologias: abrangendo pesquisa operacional, teoria dos jogos, modelos matemáticos $\mathrm{e}$ estatísticos e aplicação de tecnologias que contribuam para a definição e utilização de estratégias e procedimentos inerentes à administração; e

IV - Conteúdos de Formação Complementar: estudos opcionais de caráter transversal e interdisciplinar para o enriquecimento do perfil do formando. (BRASIL, 2005)
Teixeira e Teixeira (2006) argumentam que, com base nas novas exigências de profissionalização requeridas pelo mercado, percebe-se que os cursos de Administração devem adotar uma nova proposta de formação profissional e de ensino-aprendizagem para a consolidação do perfil generalista/polivalente. Isso parece ser a solução indicada para o desenvolvimento de competências e habilidades atualmente exigidas do profissional de administração, considerando as mudanças organizacionais e ambientais.

Para Gonçalves-Dias, Teodósio e Carvalho (2009) a Resolução $\mathrm{N}^{\circ} 1$, de 02/02/2004, que institui as diretrizes curriculares nacionais do curso de graduação em Administração, não discute explicitamente a Educação Ambiental, que está nela subentendida, porém, na medida em que sua inclusão se estabelece a partir de uma lei ordinária, que regulamenta um ditame constitucional. A Educação Ambiental, de acordo com a legislação atual e as considerações acordadas em conferências nacionais e internacionais, impõe desafios, que não são poucos, para a sua inclusão no projeto pedagógico dos cursos de Administração.

\section{Breve histórico da Educação Ambiental}

A Conferência da ONU sobre o Ambiente Humano, que foi realizada em Estocolmo, Suécia, em 1972, reconheceu a importância da Educação Ambiental como elemento crítico para o combate da crise ambiental, recomendando o treinamento de professores e o desenvolvimento de métodos e recursos apropriados para esse fim. A resolução mais importante da conferência de Estocolmo, conforme Reigota (2009), é que se deve educar o cidadão para a solução dos problemas ambientais, surgindo aí o que se convencionou chamar de educação ambiental.

Jacobi (2005) destaca o início da utilização do termo Educação Ambiental:

Embora os primeiros registros da utilização do termo educação ambiental datassem de 1948 num encontro da União Internacional para a Conservação da Natureza (UICN) em Paris, os rumos da educação ambiental são definidos a partir da Conferência de Estocolmo, na qual se recomenda o estabelecimento de programas internacionais. Em 1975, lança-se em Belgrado o Programa Internacional de Educação Ambiental, no qual são definidos os princípios e as orientações para o futuro. Desde então, três momentos marcam a trajetória do processo de 
institucionalização e pactuação da necessidade da inserção da educação ambiental no nível planetário. Cinco anos após Estocolmo, em 1977, acontece em Tbilisi, na Geórgia, a Conferência Intergovernamental sobre Educação Ambiental. Isto inicia um processo global orientado para criar as condições para formar uma nova consciência sobre o valor da natureza e para reorientar a produção de conhecimento baseada nos métodos da interdisciplinariedade e os princípios da complexidade. (JACOBI, 2005, p. 241-242)

Conforme esclarece Encarnação (2008), a partir destes fatos acima referenciados, inicia-se um processo, em nível planetário, com vistas a redimensionar e reorientar as valorações humanas na formação de uma nova postura e consciência no que se refere à natureza. Começa, então, a produção de conhecimentos, conceitos e o estabelecimento de novas relações, a partir de uma visão inovadora e abrangente de educação ambiental, mas visualizada e abordada a partir de uma multiplicidade de enfoques que, por abranger conceitos, preceitos e premissas de diversas áreas do conhecimento, envolve-se diretamente com o paradigma da complexidade assim como possui envolvimento com a visão transdisciplinar de educação.

Reigota (2009) coloca, de forma clara, que devemos considerar prioritariamente as relações econômicas e culturais que são estabelecidas entre a natureza e o homem. Assim, a Educação Ambiental deve ser entendida como uma educação política, uma educação que prepara os cidadãos para exigir justiça social, exigir ética nas relações sociais e nas relações com a natureza. Ao analisar as causas dessa crise ambiental o autor enfatiza que:

[...] o problema ambiental não está na quantidade de pessoas que existe no planeta e que necessita consumir cada vez mais os recursos naturais para se alimentar, vestir e morar. É necessário entender que o problema está no excessivo consumo desses recursos por uma pequena parcela da humanidade e no desperdício e produção de artigos inúteis e nefastos à qualidade de vida. (REIGOTA, 2009, p. 9)

Segundo Lerípio (2008), podemos ser denominados como a "sociedade do lixo", tendo em vista o grande volume de lixo gerado pela adoção de um comportamento fundamentado no "american way life", que associa a qualidade de vida ao consumo de bens materiais. Este padrão adotado alimenta a questão do consumismo, induz a produção de bens descartáveis e difunde a utilização de materiais artificiais. Ainda de acordo com o autor, nos últimos 20 anos, a população mundial cresceu menos que o volume de lixo por ela produzido.

Percebe-se que as premissas que fundamentam esse comportamento estão equivocadas, pois não é possível uma economia de crescimento ilimitado num planeta finito de recursos limitados. Não existe um estoque infinito de matérias-primas para alimentar por tempo indeterminado o atual ritmo de produção. Os ecossistemas não têm capacidade para absorver indefinidamente os detritos gerados pela sociedade industrial, seja na forma de lixo ou de poluição. Mais cedo ou mais tarde esse modelo conduz ao colapso ecológico.

$\mathrm{Na}$ leitura de Valle (2010), esse comportamento pautado nas relações de dominação e de exploração originou a sociedade consumista de recursos que hoje vivemos, que valoriza a acumulação material, a competição exacerbada e o individualismo egoísta. Para a autora, o consumismo exagerado decorre e ao mesmo tempo provoca uma crise de valores e de paradigmas que colocam em xeque o modelo atual de civilização.

Esse é apenas um exemplo de como o ambiente vem sendo tratado, em relações baseadas na prepotência e na ganância que impedem que o que é óbvio seja visto: a limitação dos recursos naturais e a inter-relação existente entre esses e com o ser humano. A ação do homem é de uma qualidade única na natureza, pois possui um enorme potencial desequilibrador. $\mathrm{O}$ homem atua sobre $\mathrm{o}$ meio ambiente não apenas para retirar o que necessita, como o fazem os outros seres vivos, mas para satisfazer necessidades que, muitas vezes, nem são suas, são fabricadas pelo sistema capitalista.

Para Loureiro (2009) a Educação Ambiental deve ser transformadora, emancipatória, ou seja, deve instrumentalizar e preparar o indivíduo para escolher livremente os melhores caminhos para a vida que quer levar em sociedade e em comunhão com a natureza. Ao dizer que a EA é transformadora, o autor está afirmando a EA enquanto práxis social que contribui para o processo de construção de uma sociedade pautada pelos patamares civilizatórios e societários distintos dos atuais, conforme desta a seguir:

A educação ambiental emancipatória e transformadora parte da compreensão de que o 
quadro de crise em que vivemos não permite soluções compatibilistas entre ambientalismo e capitalismo ou alternativas moralistas que descolam o comportamental do históricocultural e do modo como a sociedade está estruturada. (LOUREIRO, 2009, p. 94)

A matriz da Educação Ambiental emancipatória se conjuga a partir de uma matriz que compreende a educação como elemento de transformação social, inspirado no diálogo, no exercício da cidadania, no fortalecimento dos sujeitos, na superação das formas de dominação capitalista e na compreensão do mundo considerando a sua complexidade. Para Loureiro (2009) educar é emancipar, sendo que a EA só apresentará resultados coerentes se incorporar em seu fazer cotidiano a completa contextualização da complexidade ambiental. Nesse contexto reflexivo cabe à EA gerar um sentido de responsabilidade social e planetária, que observe as diferenças e desigualdades que permeiam os diversos grupos sociais.

No contexto local a Educação Ambiental no Brasil se faz tardiamente embora, como argumenta Loureiro (2009), existam registros e programas desde a década de 70 , é apenas em meados de 80 que começa a ganhar dimensões públicas de relevância, até a inclusão na Constituição Federal de 1988. Falar em ambiente era o mesmo que falar sobre a preservação do patrimônio natural, em um assunto técnico voltado para a resolução dos problemas ambientais.

Nesse sentido, a EA se inseriu primeiramente nos setores governamentais e científicos vinculados a atividades de conservação dos recursos naturais. Ela se inseriu na estrutura administrativa dos órgãos públicos de meioambiente, não sendo tratada como parte da área de educação.

Assim como diversos outros temas presentes na sociedade, o discurso ambiental, conforme Torales (2013), também foi incorporado ao discurso educativo-escolar. A Educação Ambiental, no seu breve período de surgimento, passou a fazer parte de diversos espaços do contexto social, nomeadamente, as empresas, os sindicatos, organizações estatais, ONGs, dentre outros. Esse mesmo processo acabou se somando ao processo pedagógico que ocorre nas escolas, através da incorporação da temática ambiental aos currículos escolares.

Para Brugger (1999, p. 78) "a educação ambiental é encarada na maioria das vezes como dimensão ou modalidade de educação". A autora salienta que, quando a educação ambiental é entendida dessa forma, ela não consegue ultrapassar as velhas barreiras do conservacionismo na educação. Para ela, o maior desafio posto hoje aos educadores é justamente iniciar um processo de capacitação que os torne capazes de incluir a dimensão ambiental no currículo da educação formal.

Sato e Santos (2001) argumentam que é necessário fortalecer a existência da Educação Ambiental, destacando que ela não é uma educação qualquer, muito menos uma educação para alguma coisa específica. Ela é uma identidade que necessita ser constantemente repensada e avaliada, evitando assim que caia no modismo.

A Educação Ambiental sozinha não pode ser a única transformadora, é preciso o estabelecimento de uma rede de diálogos que, na visão de Sato e Santos (2001), ainda está longe de ser concretizada, embora os autores sejam conscientes das inúmeras tentativas iniciadas. O reflexo da complexidade epistemológica na universidade, inserida no debate curricular e na necessidade de fortalecimento de uma política mais efetiva na formação de profissionais também são citados como possibilidades de ação no fortalecimento da EA.

\section{A Educação Ambiental no Ensino Superior}

Para Silva (2013) o Ensino Superior, em tese, poderia se configurar como um local privilegiado para a implantação de políticas que permitissem a construção de uma nova mentalidade ambiental, devido às suas características formativas, que são embasadas na tríade ensino, pesquisa e extensão. Mesmo assim, segundo a autora, ainda não foi capaz de impulsionar reflexões consequentes em termos de organização de propostas curriculares comprometidas com a busca de um conhecimento gerador de mudanças na racionalidade instrumental, que ainda orienta as práticas didático-pedagógicas hegemônicas.

A Educação Ambiental está gradativamente ampliando a sua presença no cenário acadêmico brasileiro. Muitos estudos têm sido efetivados em direção à construção de mapeamento das experiências e práticas de Educação Ambiental nos sistemas de educação formal, desde a Educação Básica até o Ensino Superior. Esses estudos indicam, conforme Silva (2013), uma percepção de educação ambiental relacionada com suas origens 
formais, fundamentadas na lógica comportamental e ecológico-preservacionista. A autora verifica que existe pouca visibilidade acerca de estudos e práticas fundamentadas no arcabouço teórico crítico, o que indicaria uma opção pela radicalidade da Educação Ambiental, vinculada a perspectiva emancipatória.

A partir de dados levantados junto a 27 instituições de ensino superior participantes da pesquisa denominada "Mapeamento da Educação Ambiental em instituições brasileiras de Educação Superior: elementos para discussão sobre políticas públicas" (RUPEA, 2005), observa-se que a Educação Ambiental aparece mais presentemente no Ensino de Graduação, contrariando uma percepção de que ela estaria mais ligada aos estudos de pós-graduação, sendo que a sua oferta ocorre com maior frequência de forma obrigatória, o que também contraria o senso comum de que ela seria oferecida frequentemente de forma eletiva ou optativa.

A pesquisa realizada também permite apontar a presença da EA no ensino de graduação mais vinculada ainda às disciplinas clássicas das ciências naturais, ou no máximo sua inserção nas discussões das ciências humanas nos cursos de Geografia e Pedagogia e, mais recentemente, no curso de Turismo.

O cenário traçado pela pesquisa indicou ainda as principais dificuldades, os elementos facilitadores e as principais proposições no campo da política pública de EA. Em termos de dificuldades, os principais elementos citados foram: 1) rigidez no meio acadêmico; 2) falta de recursos financeiros, infraestrutura e pessoal; 3) falta de políticas públicas e institucionais; 4) falta de preparo dos profissionais para a prática da EA; 5) desconhecimento da legislação sobre EA; 6) falta de pesquisa, sistematização e divulgação das experiências de EA; 7) falta de arcabouço teórico e metodológico; 8) outras dificuldades (RUPEA/MEC, 2005).

Em relação aos elementos facilitadores, foram identificados os seguintes grupos: 1) relevância da EA para a comunidade universitária; 2) pressão ou interesse da sociedade em relação a EA; 3) apoio e articulação institucional; 4) parcerias intra e interinstitucional; 5) espaços de diálogo e integração das atividades na IES; 6) existência de um campo de saber em construção; 7) autonomia de pensamento e ação; 8) epistemologia ambiental; 9) existência de financiamentos e de políticas públicas; 10) responsabilidade socioambiental da universidade (RUPEA/MEC, 2005).

Quanto às prioridades na elaboração de políticas públicas para consolidação da EA nas IES foram identificados os seguintes grupos de categorias: 1) atuação transversal e enfoques inter e transdisciplinar; 2) processos de formação ambiental e de educadores ambientais; 3) necessidade de políticas públicas específicas; 4) instrumentos e procedimentos institucionais; 5) processos e estruturas de diálogo e socialização acadêmica em EA na IES; 6) ampliação de recursos financeiros; 7) articulação interinstitucional e em redes; 8) programas de EA; 9) avaliação, sistematização e divulgação das experiências em EA; 10) reformulação curricular (RUPEA/MEC, 2005)

$\mathrm{Na}$ leitura de Silveira (1998), a Universidade tem um importante papel na discussão de questões referentes à EA, primeiramente, porque acumula as funções de ensino, pesquisa e extensão, sendo responsável pela formação dos profissionais que irão atuar no mercado de trabalho. Em segundo lugar, por ser um local de diálogo por excelência, onde se trabalha na construção de novos conhecimentos e novas realidades socioambientais. Em terceiro, destaca que a Universidade é um local de pesquisa por excelência e, finalmente, aponta a crescente aceitação tanto da inter quanto da transdisciplinaridade como alternativas de novas composições curriculares. Nesse contexto, a Educação Ambiental encontra um ambiente propício onde possa fluir e se desenvolver em abrangência e profundidade.

A Educação Ambiental assume, assim, de maneira crescente, a forma de um processo intelectual ativo, enquanto aprendizado social, baseado no diálogo e interação em constante processo de recriação e reinterpretação de informações, conceitos e significados, que se originam do aprendizado em sala de aula ou da experiência pessoal do aluno. A abordagem do meio ambiente na escola passa a ter um papel articulador dos conhecimentos nas diversas disciplinas, num contexto no qual os conteúdos são ressignificados. Ao interferir no processo de aprendizagem e nas percepções e representações sobre a relação entre indivíduos e ambiente nas condutas cotidianas que afetam a qualidade de vida, a EA promove os instrumentos para a construção de uma visão crítica, reforçando práticas que explicitam a necessidade de problematizar e agir em relação aos problemas socioambientais, tendo como horizonte, a partir de uma compreensão dos conflitos, partilhar de uma 
ética preocupada com a justiça ambiental.

É consenso na comunidade internacional, conforme destacado por Reigota (2009), que a Educação Ambiental deve estar presente em todos os espaços que educam o ser humano. As universidades estão incluídas nesses espaços, pois dedicam-se à formação de profissionais que possam atuar nas diversas áreas do conhecimento voltadas para o meio ambiente:

A educação ambiental, como perspectiva educativa, pode estar presente em todas as disciplinas quando analisa temas que permitam enfocar as relações entre a humanidade e o meio natural e as relações sociais, sem deixar de lado as suas especificidades. (REIGOTA, 2009, p. 45)

A Educação Ambiental passa a ser percebida como um meio educativo que favorece a compreensão articulada das dimensões ambiental e social, a problematização da realidade e a busca das origens da crise civilizatória. A Lei no 9795/99 que institui a Política Nacional de Educação Ambiental em seu artigo $2^{\circ}$ descreve:

Art. $2^{\circ}$ A educação ambiental é um componente essencial e permamente da educação nacional, devendo estar presente, de forma articulada, em todos os níveis e modalidades do processo educativo, em caráter formal e não-formal. (BRASIL, 1999)

Conforme se destaca no texto da lei, a Educação Ambiental deve estar presente em todos os níveis da educação, seja ela formal ou não. Dessa forma os cursos superiores se inserem nesse contexto com um papel de destaque, ainda mais se considerarmos a responsabilidade na formação de egressos que sejam dotados de responsabilidade com os problemas socioambientais e com a preservação do meio ambiente no desempenho das suas atribuições profissionais.

Posteriormente foi aprovada a Resolução $\mathrm{n}^{\circ}$. 2, de 15 de junho de 2012 que estabeleceu as Diretrizes Curriculares Nacionais para a Educação Ambiental. Em seu artigo 16 indica que a Educação Ambiental deve estar presente nos currículos da Educação Básica e da Educação Superior por meio da transversalidade, mediante temas relacionados com o meio ambiente e a sustentabilidade socioambiental; ou "como conteúdo dos componentes já constantes do currículo" ou ainda "pela combinação de transversalidade e de tratamento nos componentes curriculares".

A inserção da Educação Ambiental numa perspectiva crítica, ocorre na medida em que o professor assume uma postura reflexiva. Isto potencializa entender a educação ambiental como uma prática político-pedagógica, representando a possibilidade de motivar e sensibilizar as pessoas para transformar as diversas formas de participação em potenciais fatores de dinamização da sociedade e de ampliação da responsabilidade socioambiental.

\section{A Educação Ambiental no ensino de Administração}

Barbieri (2004) ressalta que, na maioria dos programas dos cursos superiores, a Educação Ambiental não passa de uma atividade isolada por ocasião do dia do meio ambiente ou de programas de coleta seletiva de lixo, gerados nas dependências da escola. O quadro não é diferente no âmbito dos cursos de Administração. $\mathrm{O}$ atendimento às normas legais, que vem crescendo desde meados da década de 1970, pouco repercute nos cursos superiores da área, pois muitos problemas existentes eram e continuam sendo considerados típicos da área de produção, a serem resolvidos apenas pelos especialistas da área.

A lentidão em trazer para dentro dos cursos de Administração as questões ambientais se deve em muito à dificuldade de mudar comportamentos típicos, solidificados ao longo de décadas, de empresários e administradores que sempre enxergam as oportunidades e os investimentos na melhoria das práticas ambientais como gastos ou custos. Precisamos superar as condições históricas de desigualdades estruturais fundamentadas num modelo de relação sociedade-natureza, baseada nos marcos da racionalidade capitalista, que nega a possibilidade de outra forma de relações sociais que não seja pela racionalidade instrumental.

Teixeira e Teixeira (2006) destacam que no contexto atual, verifica-se um posicionamento das organizações no sentido de inserção da variável ecológica em sua política de atuação, em face das pressões do mercado, provocando mudanças positivas não só no ambiente da empresa como no meio externo, afetando a comunidade, funcionários, fornecedores, etc. Expande-se a ideia de responsabilidade social da empresa e a necessidade de adequação e mudanças de valores. A variável ambiental, entendida como custo para muitos, passa a ser vista como uma oportunidade de negócios para alguns. 
A institucionalização da temática Educação Ambiental nas escolas de graduação em Administração tem variado bastante, conforme o contexto e as características culturais das diferentes instituições. Em algumas escolas a iniciativa se constrói a partir da atuação de determinados professores que introduzem, de forma gradual e progressiva, discussões e abordagens relacionadas com a questão ambiental nas suas respectivas disciplinas. A associação de departamentos da mesma escola ou de diferentes escolas também tem sido utilizada como abordagem para viabilizar a criação das competências multidisciplinares requeridas para o ensino da gestão ambiental. Independentemente da estratégia de institucionalização adotada, um dos fatores de sucesso parece ser a existência de um professor ou um grupo de professores altamente comprometidos e envolvidos com a difusão das discussões ambientais no ensino de Administração (BARBIERI, 2004; KRUGLIANSKAS, 1993).

Existe uma efervescência dentro da área acadêmica para atender à demanda do mercado por profissionais habilitados, principalmente para a formação de um corpo docente mais preparado para lidar com a questão ambiental. Kruglianskas (1993) alerta que as escolas de Administração, como formadoras de futuros dirigentes e executivos, ampliam a sua responsabilidade na capacitação desses profissionais e também na sua sensibilização para as questões socioambientais.

Um dos fatores que levaram à introdução das questões ambientais na graduação em Administração diz respeito à elaboração das normas da série ISO 14.000 desde 1996 e dos problemas relacionados com as barreiras técnicas ao comércio, conforme se depreende do crescente número de artigos em revistas ligados à gestão empresarial. Porém, não se pode dizer que está se praticando a Educação Ambiental apenas porque em algum momento do curso se discute a norma ISO $14.000 \mathrm{e}$ a legislação ambiental.

Com base nas novas exigências de profissionalização requeridas pelo mercado, percebe-se que os cursos de Administração devem adotar uma nova proposta de formação profissional e de ensino-aprendizagem para a consolidação do perfil generalista/polivalente. Isso parece ser a solução indicada para o desenvolvimento de competências e habilidades atualmente exigidas do profissional de administração, considerando as mudanças organizacionais e ambientais.

O mundo está se tornando cada vez mais complexo e os estilos de pensamento devem acompanhar esta complexidade. $O$ método de análise deve se basear sobre nosso melhor recurso: a capacidade de pensamento crítico e reflexivo. É necessário desenvolver a capacidade criativa, o pensamento complexo e a consciência ambiental, ao mesmo tempo, de forma a permitir analisar a realidade de uma organização respeitando o seu caráter multifacetado e suas complexas relações com o ambiente onde a mesma está inserida. É preciso aprender a aprender, conforme destaca Demo (2010):

Avaliar, assim como ensinar, é um ato político e, para que seja adequadamente político, precisa se instrumentalizar no conhecimento. Não é possível gestar cidadania competente sem manejo adequado do conhecimento, o que leva de imediato a valorizar didáticas reconstrutivas que privilegiam o saber pensar e o aprender a aprender. (DEMO, 2010, p. 65)

A tarefa de trabalhar com a Educação Ambiental não é fácil, pois exige um repensar constante das práticas pedagógicas, pois como argumenta Freire (2013) não podemos superar as contradições existentes nas relações sociais vigentes por meio de uma educação reprodutória da sociedade capitalista, a qual denomina de "ensino bancário", ou "falso ensinar", onde apenas se ajustam condutas e adaptam as pessoas para aceitarem a sociedade tal como ela é e onde são deformadas a criatividade tanto do educando como do educador.

Giroletti (2005) revela que o ensino de Administração no Brasil apresenta alguns problemas que precisam ser analisados, um deles é a especialização excessiva adotada por alguns cursos no intuito de atrair maior clientela e diferenciar-se dos demais. Outro problema está relacionado à ênfase excessiva no caráter prático do conhecimento, fazendo com que alguns cursos procurem "clonar" a empresa privada:

Ouve-se com frequência que o curso modelar de Administração é aquele que prepara o aluno para o mercado ou aquele que oferece um conhecimento prático ou simula a atmosfera futura da empresa onde irá trabalhar. Como as universidades podem oferecer isso se o mercado e o conhecimento prático de hoje não serão aqueles de amanhã? Não há como negar que o mercado e as empresas modificam-se com extrema 
velocidade. Por isso, dificilmente, o que se ensina hoje na universidade valerá amanhã, ao final do curso, quando o aluno ingressar no mercado de trabalho. (GIROLETTI, 2005, p. 118)

Torna-se necessário destacar uma possibilidade de ação frente aos problemas apresentados: o ensino teórico, o desenvolvimento do raciocínio, da capacidade de abstração, da criatividade, da inovação, do senso crítico e da capacidade analítica devem ter precedência sobre a prática (GIROLETTI, 2005). O ensino não deve limitar-se a oferecer aos alunos modelos já constituídos, mas estimulá-los a buscar e a testar novos caminhos.

Refletir sobre a complexidade ambiental abre um estimulante espaço para compreender a formação de novos atores sociais que se mobilizam para a apropriação da natureza, para um processo educativo articulado e compromissado com a sustentabilidade e a participação, apoiado numa lógica que privilegia o diálogo e a interdependência de diferentes áreas do saber. Mas também oportuniza o questionamento dos valores $\mathrm{e}$ premissas que norteiam as práticas sociais prevalecentes, implicando numa mudança na forma de pensar, uma transformação no conhecimento e nas práticas educativas, principalmente nas universidades (JACOBI, 2005).

A universidade não pode abrir mão da sua responsabilidade de formar o cidadão e a pessoa humana na sua plenitude. A universidade deve auxiliar na substituição do pensamento linear pelo pensamento da complexidade. São características do pensamento da complexidade: a compreensão que o conhecimento das partes depende do conhecimento do todo e que o conhecimento do todo depende do conhecimento das partes; o reconhecimento e o exame dos fenômenos de forma multidimensional; o reconhecimento e o trato de realidades que são, ao mesmo tempo, solidárias e conflituosas e, por último, o respeito a diferença enquanto reconhece a unicidade. Conforme afirma Morin (2011), a universidade:

[...] conserva, memoriza, integra, ritualiza uma herança cultural de saberes, ideias, valores; regenera essa herança ao reexaminá-la, atualizála, transmiti-la. Gera saberes, ideias e valores que passam, então a fazer parte da herança. (MORIN, 2011, p. 81)

Como educadores, no entender de Moraes (2008), precisamos colaborar fortemente para que haja um pouco mais de luz na consciência humana. Precisamos catalisar as reformas do pensamento e da consciência sugeridas por Edgar Morin para que possamos ter uma vida mais plena e garantir a sustentabilidade ecológica e o desenvolvimento do planeta para todos que dele necessitem. Precisamos ainda resgatar a ideia de que os sistemas educacionais necessitam estar a serviço de um tipo de sociedade mais aceitável.

Para conseguir alcançar essa finalidade, será necessário oferecer uma educação que desenvolva, prioritariamente, processos reflexivos, criativos e críticos voltados para o desenvolvimento da autonomia, da criatividade e da solidariedade. Uma educação que instrumentalize o aprendiz para que ele possa perceber o verdadeiro sentido das coisas, para que ele possa evoluir e, principalmente, possa aprender a fazer escolhas que sejam mais conscientes e responsáveis para com a vida no planeta (MORAES, 2008).

Pensando mais detalhadamente a questão educacional, percebe-se que é necessário colocar em prática uma percepção da Educação Ambiental como elemento de transformação social, que é realizada a partir de diálogos, do respeito a natureza a ao próximo e que, por estar fundada em valores completamente divergentes dos valores atuais, precisa causar uma ruptura com o modo de vida atual que está nos levando a um desastre ecológico sem precedentes.

Esse entendimento da realidade baseado numa perspectiva complexa colabora para uma prática pedagógica em Educação Ambiental, que incorpore os temas da realidade dos educandos assim como a realidade da universidade, possibilitando a geração de novos comportamentos dos futuros administradores diante do contexto socioambiental, sendo que isso demanda uma postura transdisciplinar.

\section{Considerações finais}

A questão ambiental ocupa hoje grande parcela dos esforços dos administradores, exigindo um novo perfil do profissional, alguém que consiga articular e organizar uma estrutura administrativa, que comporte uma efetiva condução de todos os setores das organizações no caminho de um trabalho pautado, principalmente, pela responsabilidade social e ambiental. Para que esse objetivo possa ser alcançado, torna-se necessário trabalhar com uma mudança de valores e de postura dos futuros profissionais, de forma que os mesmos possam, como argumentam Teixeira e Teixeira (2006), 
contribuir para a resolução dos desequilíbrios socioambientais que estamos vivendo. Os currículos dos cursos de administração - que são voltados a preparar gestores para as organizações e empreendedores - devem conter em seu âmago disciplinas ou eixos de conhecimento que permeiem a Educação Ambiental neste contexto, sob o risco de estar se formando e reproduzindo profissionais despreparados para o enfrentamento da questão.

Considerando o exposto, entendo que é importante a preparação de administradores que sejam qualificados e que tenham competência para implementar ações que possibilitem o uso dos recursos naturais de forma mais racional $\mathrm{e}$ equilibrada, possibilitando assim a preservação ambiental e a justiça social. Caberá à instituição de ensino sistematizar os conhecimentos gerados na construção de novos saberes, de forma a torná-los aplicáveis em ações conscientes dentro de um contexto de profunda consciência social.

\section{Referências}

ALVAREZ, A. M. de; PHILIPPI JR., A.; ALVARENGA, A.T. de. O pensamento complexo e desafios aos processos investigativos. Revista Brasileira de Ciências Ambientais, ${ }^{\circ}$ 18, p. 67-76, dez. 2010.

ANDRADE, R. O. B. História e Perspectivas dos Cursos de Administração do Brasil. In: II Seminário Nacional sobre Qualidade e Avaliação dos Cursos de Administração, 27-29 de agosto de 1997, Vitória. Anais... Vitória, 1997, p. 10-49.

BARBIERI, J. C. Educação ambiental e a gestão ambiental em cursos de graduação em Administração: objetivos, desafios e propostas. Revista de Administração Pública, 38 (6), p. 919946, 2004.

BRASIL, Ministério da Educação. Resolução $N^{o}$ 04/2005, de 13 de julho de 2005. Institui as Diretrizes Curriculares Nacionais do Curso de Graduação em Administração, bacharelado, e dá outras providências. Disponível em: $<$ http://portal.mec.gov.br/cne/arquivos/pdf/rces01_0 4.pdf>. Acesso em: 20 fev. 2017.

BRASIL, Lei $n^{\circ}$ 9.795/1999 de 27 de abril de 1999. Dispõe sobre a educação ambiental, institui a Política Nacional de Educação Ambiental e dá outras providências. Diário Oficial da República
Federativa do Brasil, Brasília. Disponível em: <http://www.planalto.gov.br/ccivil_03/Leis/L9795 m. Acesso em: 14 dez. 2016.

BRUGGER, P. Educação ou adestramento ambiental? $2^{\mathrm{a}}$ ed. Florianópolis: Livraria e Editora Obra Jurídica, 1999.

DEMO, P. Avaliação Qualitativa. $10^{\mathrm{a}} \mathrm{ed}$. Campinas: Autores Associados, 2010.

ENCARNAÇÃO, F. L. Complexidade e Educação Ambiental. Revista Espaço Acadêmico, ${ }^{\circ}$ 91, dez. 2008. Disponível em:

<http://www.espacoacademico.com.br/091/91encar nacao.pdf $>$. Acesso em: 17 out. 2016.

FREIRE, P. Pedagogia da Autonomia: saberes necessários à prática educativa. $47^{\mathrm{a}} \mathrm{ed}$. Rio de Janeiro: Paz e Terra, 2013.

GIROLETTI, D. Administração no Brasil:

Potencialidades, Problemas e perspectivas. Revista de Administração de Empresas, RAE, v. 45, Edição Especial Minas Gerais, p. 116-120, 2005.

GONÇALVES-DIAS, S. L. F.; TEODÓSIO, A. dos S. de S.; CARVALHO, S. Consciência Ambiental: um estudo exploratório sobre suas implicações para o ensino de Administração. RAE-eletrônica, vol. 8, n. 1, jan-jun/2009. Disponível em: <http://www.rae.com.br/eletronica.> Acesso em: 09 maio. 2015.

JACOBI, P. R.. Educação Ambiental: o desafio da construção de um pensamento crítico, complexo e reflexivo. Educação e Pesquisa, São Paulo, v. 31, $\mathrm{n}^{\circ} 2$, p. 233-250, maio/ago 2005.

KRUGLIANSKAS, I. Ensino da gestão ambiental em escolas de Administração de Empresas: a experiência da FEA/USP. In: Encontro Nacional de Gestão Empresarial e Meio Ambiente, 1993, São Paulo. Anais..., São Paulo: FEA/USP, EAESP/FGV, 1993.

LERIPIO, A. A. Gerenciamento de resíduos. 2004. Disponível em:

<http://www.eps.ufsc.br/ lgqa/Coferecidos.html>. Acesso em: 28 nov. 2014.

LOUREIRO, C. F. B. Trajetória e fundamentos da educação ambiental. $3^{\text {a }}$ ed. São Paulo: Cortez, 2009. 
MEC. RUPEA. Relatório Final da Pesquisa:

Mapeamento da Educação Ambiental em instituições brasileiras de Educação Superior: elementos para discussão sobre políticas públicas. Brasília: MEC, 2005.

MORAES, M. C. Pensamento Eco-Sistêmico: educação, aprendizagem e cidadania no século XXI. $2^{\mathrm{a}}$ ed. Petrópolis, RJ: Vozes, 2008.

MORIN, E. A cabeça bem-feita: repensar a reforma, reformar o pensamento. 19a ed. Rio de Janeiro: Bertrand Brasil, 2011.

PIZZINATTO, N. K. Prática Empresarial dentro de uma universidade para o curso de Administração de Empresas. In: III Encontro Nacional dos Cursos de Graduação em Administração, 1992, Belo Horizonte. Anais..., Belo Horizonte, MG, 1992.

SATO, M.; SANTOS, J. E. dos. Um breve itinerário pela educação ambiental. In: SATO, M.; SANTOS, J. E. dos. (Org.). A contribuição da educação ambiental. $1^{\mathrm{a}}$ ed. São Carlos: EdUFSCar, 2001, v. 1, p. 1-12.

SILVA, M. L. da. A educação ambiental no ensino superior brasileiro: do panorama nacional às concepções de alunos (as) de pedagogia na Amazônia. REMEA, Revista do Curso de PósGraduação em Educação Ambiental da FURG, vol. Especial, p. 18-22, março de 2013.
TEIXEIRA, A. C. E. de A.; TEIXEIRA, H. de A. O ensino de Administração e a Educação Ambiental: algumas reflexões sobre os currículos e a importância da formação de agentes multiplicadores nas organizações. Revista de Gestão e

Planejamento, Salvador, ano7, $\mathrm{n}^{\circ} 13$, p. 14-21, janjun 2006.

REIGOTA, M. O que é Educação Ambiental. $2^{\mathrm{a}}$ ed. São Paulo: Editora Brasiliense, 2009.

SILVEIRA, D. L. da. Educação Ambiental e conceitos caóticos. In: PEDRINI, A. G. (org.). Educação ambiental: reflexões e práticas contemporâneas. $2^{\mathrm{a}}$ ed. Petrópolis: Vozes, 1998, p. 188-259.

TORALES, M. A. A inserção da educação ambiental nos currículos escolares e o papel dos professores: da ação escolar a ação educativocomunitária como compromisso político-ideológico. REMEA, Revista do Curso de Pós-Graduação em Educação Ambiental da FURG, vol. Especial, p.117, março de 2013.

VALLE, L. M. C. Educação Ambiental e Ensino Jurídico: concepções e práticas docentes na constituição do perfil do egresso. 2010. 225 f. Tese de Doutorado. Programa de Pós Graduação em Educação Ambiental da Universidade Federal do Rio Grande Rio Grande - FURG. Rio Grande.

\section{Sobre os autores}

Suzana de Oliveira Malta: Doutora em Educação Ambiental pela Universidade Federal do Rio Grande (FURG). Professora da Universidade Federal do Rio Grande (FURG). Membro do Grupo de Estudos da Complexidade - GEC/CNPq - Rio Grande - RS.

Humberto Calloni: Doutor em Educação pela Universidade Federal do Rio Grande do Sul (UFRGS). Professor e pesquisador da Universidade Federal do Rio Grande (FURG). Líder do Grupo de Estudos da Complexidade GEC/CNPq - Rio Grande - RS.

Submetido em abril de 2017.

Aprovado em janeiro de 2018. 